\title{
SURGICAL OUTCOMES OF SPINAL GUNSHOT WOUNDS
}

\author{
๑ Alparslan KIRIK, @ Soner YAȘAR
}

University of Health Sciences Turkey, Gülhane Training and Research Hospital, Clinic of Neurosurgery, Ankara, Turkey

\begin{abstract}
Objective: Although gunshot injuries to the spine and spinal cord are usually not fatal, but these are associated with significant morbidities. The management of spinal gunshot wounds (SGW) is controversial. Some surgeons prefer early surgery, while others recommend late surgery, if necessary. The aim of this study was to analyse the results of patients who underwent treatment for SGW and discuss this with the current literature.

Materials and Methods: A retrospective study of SGW patients treated at a single institution was conducted. The study included a total of 32 patients over a 10 -year period. Preoperative and early postoperative clinical and radiological data were analysed with the surgical technique used during the management of patients.

Results: Overall, 27 patients underwent surgical treatment and five patients underwent conservative management. The mean follow-up duration was $12 \pm 4$ months. Eighteen patients were injured by bullet, while 14 patients were injured by shrapnels. Injury occurred at lumbar spine in 17 patients, thoracolumbar region in six, cervical spine in five, thoracic spine in three and lumbosacral region in one patient. Five patients underwent continuous lumbar drainage and cerebrospinal fluid (CSF) infection was seen in two patients. However, no patient died at the end of treatment period.

Conclusion: Patients with SGW should undergo comprehensive clinical and radiological assessments for surgical treatment. The main indications for early surgical intervention are CSF fistula and progressive neurological deficits. Stabilisation surgery should be the treatment option for patients with spinal instability.
\end{abstract}

Keywords: Spine, gunshot wound, surgery, morbidity

\section{INTRODUCTION}

Spinal gunshot wounds (SGW) are an important health problem in both military and civilian surroundings ${ }^{(1-3)}$. SGW account for $13 \%$ to $17 \%$ of all spinal cord injuries each year ${ }^{(4)}$. These injuries may affect both the spinal column and spinal cord(5,6). Clinical presentation of SGW depends on the site and type of injury. Wounds that are not penetrated or involved the spinal cord usually do not cause neurological deficits. Severe neurological deficits such as paraplegia or quadriplegia occur if the spinal cord is damaged. However, SGW to the upper cervical spine, or associated with thoracic or abdominal injuries, may cause mortality ${ }^{(7)}$.

Neurological examination is the first step of evaluation of SGW after the first aid. Spinal shock may occur when the spinal cord is totally damaged. The signs of a spinal cord injury are weakness and sensorial disturbances. Radiological investigation is essential for the exact diagnosis and possible indications of surgery ${ }^{(8)}$.

Computed tomography (CT) and magnetic resonance imaging (MRI) are used for the evaluation of SGW(9). Metallic and other fragments located in and around the spinal column are shown through CT scans. CT scan also reveals bony damage and gives information about the stability of spinal column. MRI should be obtained after the CT scan to rule out the presence of any metallic fragment in the body. MRI is contraindicated in patients having metallic fragments in the spine and spinal cord. MRI is also essential for the evaluation of the spinal cord damage and detection of cerebrospinal fluid (CSF) fistula or collection (pseudomeningocele). It can also be used for the detection of spinal or paraspinal abscess formation in the late period of SGW $(1-4,6)$.

Surgical treatment is opted in SGW in case of the following: if there is CSF fistula, early and progressive neurological deficits associated with significant spinal cord compression and spinal instability ${ }^{(10,11)}$. The surgical technique involves decompression of the spinal cord and spinal roots, closure of dura mater and reconstruction of the spinal column by stabilisation surgery. The aim of this study is to present our experience of SGW and discuss our results with the current literature.

\section{MATERIALS AND METHODS}

In this study, 32 patients with SGW, who underwent conservative and surgical treatment between 2010 and 2019, were reviewed

Address for Correspondence: Soner Yaşar, University of Health Sciences Turkey, Gülhane Training and Research Hospital, Clinic of Neurosurgery, Ankara, Turkey Phone: +90 5326379543 E-mail: dr.soneryasar@gmail.com Received: 16.07.2020 Accepted: 28.07.2020

ORCID ID: orcid.org/0000-0001-9331-0144 
retrospectively. All the patients were operated by the surgical team in a single university hospital. Ethical approval for this study was obtained from our institutional ethics committee [University of Health Sciences Gülhane Medical Research Ethics Committee Medical Research Ethics Committee (approval date: 30.06.2020, approval number: 2020/296)]. Written informed consent was obtained to publish the data.

Patients with SGW, having all clinical, radiological and surgical data, follow-up period of at least 6 months and age between 18 and 60 years were included in the study. Patients who had previous surgery done in another centre, children and patients without enough clinical and radiological data were excluded from the study.

Plain X-rays of the patients obtained just after the injury were reviewed. CT and MRI scans of the patients were evaluated carefully. Surgical data and clinical outcomes were retracted and analysed. Results of CSF cultures were recorded.

\section{RESULTS}

A total of 32 patients (one female, 31 males) with a mean age of 30.03 years (ranged between 21 and 54 years) were treated in our department. The mean follow-up period was 12 months. Clinical and radiological examinations of the patients determined the type of treatment as conservative or surgical. Plain X-rays and CT scans were obtained from all patients (Figures 1,2 and 3). MRI was performed in 25 patients (Figure 4); seven patients did not undergo MRI because of the presence of metallic fragments within the body. Locations of spinal injuries were as follows: lumbar spine (17 patients), thoracolumbar region (six patients), cervical spine (five patients), thoracic spine (three patients) and lumbosacral region in one patient. Bullet injury was occurred in 18 patients and shrapnel injury

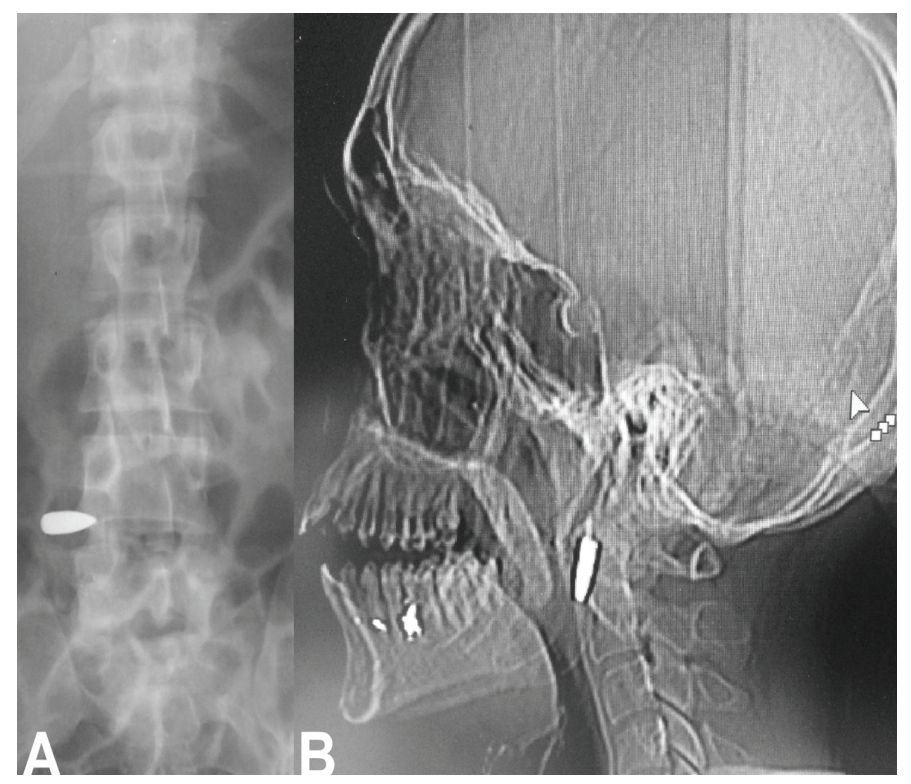

Figure 1. Radiographs of a patient with lumbosacral SGW (A) and cervical SGW (B). There was a bullet just in front of the C1 level (B) SGW: Spinal gunshot wound (grenade, landmine and handmade explosive) in 14 patients

(Table 1). Twenty-five patients were military persons who were

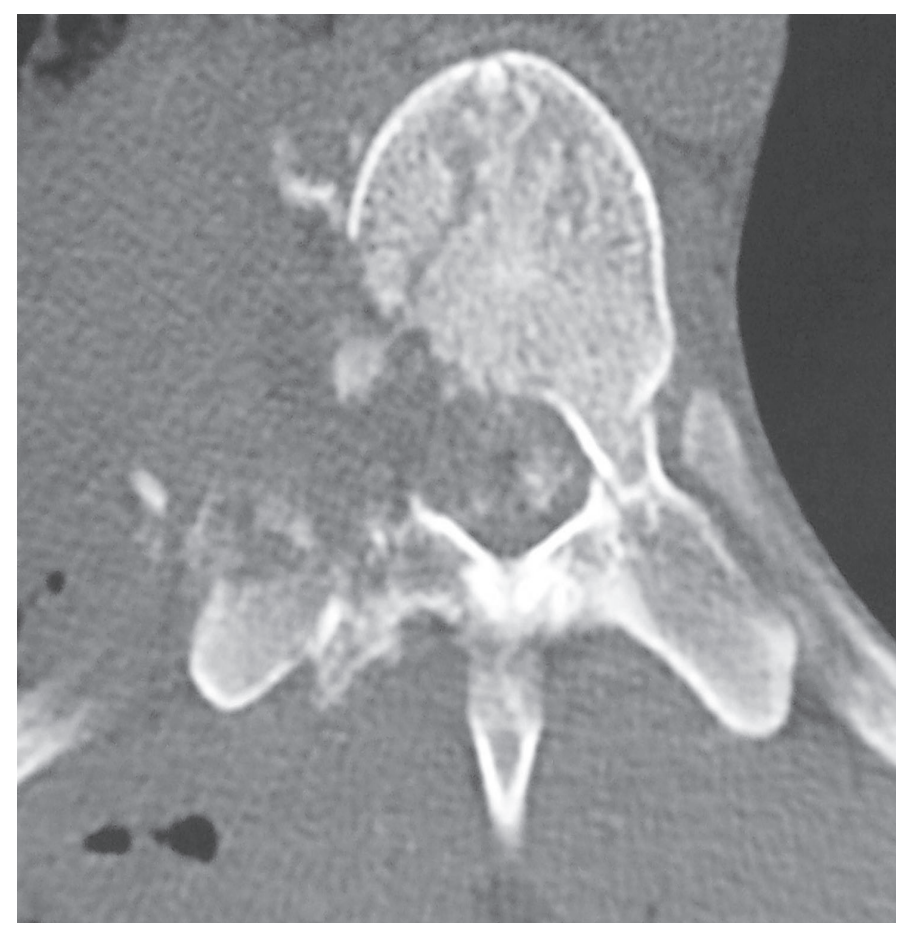

Figure 2. CT scan of a patient with SGW at thoracic level. Right side of the body and the pedicle of the vertebrae were significantly damaged

CT: Computed tomography, SGW: Spinal gunshot wound

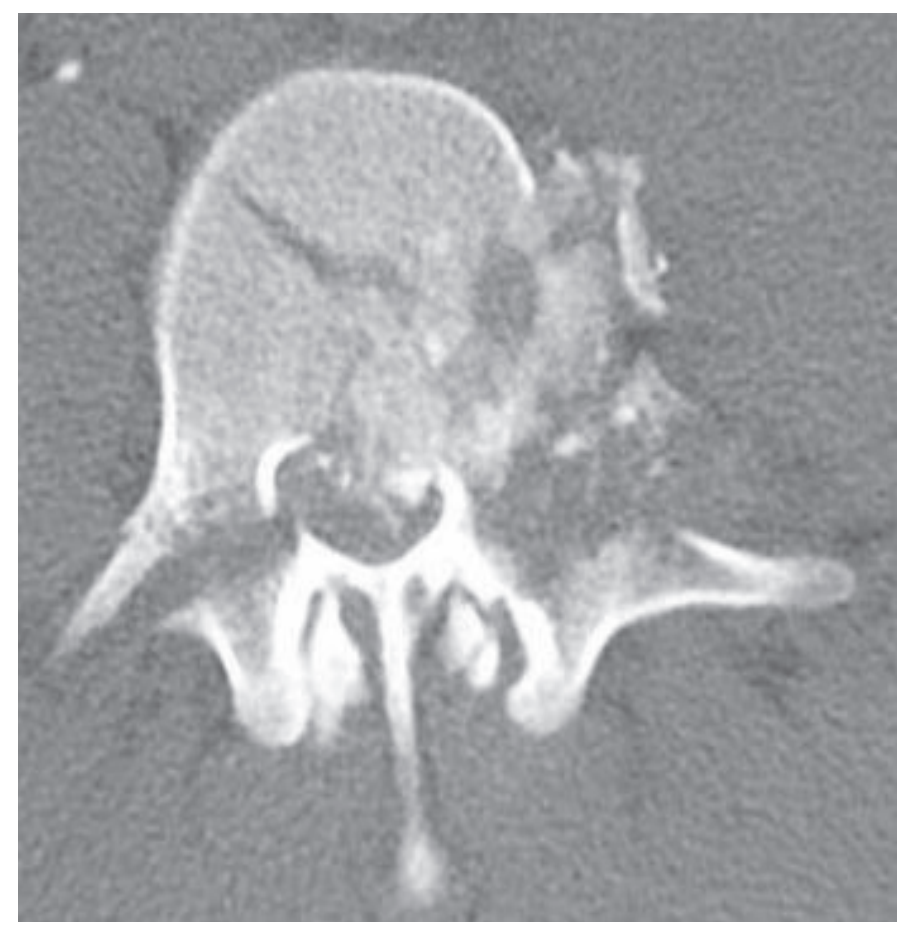

Figure 3. CT scan of a patient with SGW at lumbar level. Body and left pedicle were damaged and there were bone fragments in the spinal canal

CT: Computed tomography, SGW: Spinal gunshot wound 


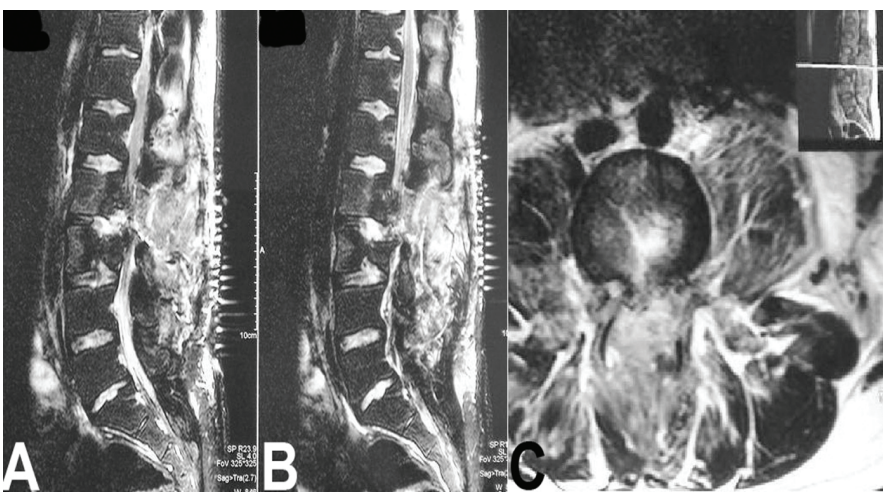

Figure 4. Postoperative sagittal (A, B) and axial (C) T2-weighed MRI scans of a patient with SGW at L3 level. Spine, spinal cord and paravertebral soft tissues were significantly damaged by a high-velocity bullet

SGW: Spinal gunshot wounds

Table 1. The demographic, radiological and surgical characteristics of patients with SGW

\begin{tabular}{ll}
\hline Variable & Number (\%) \\
\hline Gender & $1(3 \%)$ \\
\hline Female & $31(97 \%)$ \\
\hline Male & $32(100 \%)$ \\
\hline Total & \\
\hline Age (years) & $19(59 \%)$ \\
\hline$<30$ & $10(32 \%)$ \\
\hline $30-45$ & $3(9 \%)$ \\
\hline$>45$ & $32(100 \%)$ \\
\hline Total & \\
\hline Injury level & $17(53 \%)$ \\
\hline Lumbar & $6(19 \%)$ \\
\hline Thoracolumbar & $5(16 \%)$ \\
\hline Cervical & $3(9 \%)$ \\
\hline Thoracic & $1(3 \%)$ \\
\hline Lumbosacral & $32(100 \%)$ \\
\hline Total & $27(100 \%)$ \\
\hline Cause of injury & $18(56 \%)$ \\
\hline Bullet & $14(44 \%)$ \\
\hline Shrapnel & $32(100 \%)$ \\
\hline Total & $3(15 \%)$ \\
\hline Indication of surgery & \\
\hline CSF fistula & $(7 \%)$ \\
\hline Spinal instability & \\
\hline Abscess & \\
\hline Foreign body & \\
\hline Progressive neurological deficits & \\
\hline Total & \\
\hline SGW: Spinal gunshot wounds, CSF: Cerebrospinal fluid \\
\hline Sul
\end{tabular}

injured in the battlefields by bullets, grenades and landmines. Seven patients were civilians who were injured by bullets and handmade explosives during the terrorist activities.

Five patients were treated conservatively and 27 (84.37\%) patients underwent surgical treatment. Surgical treatment was opted for the following reasons: CSF leakage in 11 (40.74\%) patients, spinal instability in seven patients, spinal abscess in three patients, foreign body in four patients and progressive neurological deficit in two patients. Decompression with duraplasty was performed in 20 patients and simple decompression was performed in seven patients. Stabilisation surgery with decompression and fusion was performed in seven patients. Continuous lumbar drainage was performed in five patients, and microorganism was isolated in two patients. The microorganisms were Klebsiella and Pseudomonas species. These patients were treated with relevant antibiotics. The mean duration of lumbar drainage was 6 days. No patient was died after surgery or in the postoperative follow-up period. Patients underwent periodical radiological follow-up using $\mathrm{CT}$ scans and MRI if necessary. Paraplegia was found as the common sequela of SGW in 14 patients and quadriplegia was found in two patients. Minor neurological deficits were detected in nine patients after surgery, who were existed in the preoperative period.

\section{DISCUSSION}

The results of 32 patients with SGW were presented in our study. Most of the patients were military persons younger than 30 years. Surgical treatment was performed in $84 \%$ of patients. The main indication of surgery in our series was CSF fistula and no mortality was encountered after the treatment. Stabilisation surgery was performed in seven patients with spinal instability after the injury.

SGW are common in the military practice ${ }^{(3,7,8,12)}$. Injuries are mainly caused by bullets and shrapnels in the battlefields $s^{(7,12,13)}$. Today, landmines and handmade explosives are frequently used in the terrorist activities. Thus, both military persons and civilians may be injured by these guns ${ }^{(1,2,12)}$. In our series, 25 patients were from the army and were injured by bullets and shrapnels. Bullet was found to be the most common injured agent.

Gunshot wounds are classified as low-velocity or high-velocity based on the speed of projectile ${ }^{(12)}$. Low-velocity wounds are caused by small-calibre handguns and thus there are less tissue damage and spinal instability than high-velocity wounds ${ }^{(2,3)}$. The damage created by a gunshot depends on the kinetic energy of the projectile ${ }^{(3,12)}$. Shrapnels are also considered as lowvelocity agents. However, high-velocity wounds are secondary to missiles that are mostly used in military practice such as rifles. These wounds create severe damage and cavity in the body and the risk of infection is high because of the large injury area and damaged tissue ${ }^{(12,14,15)}$. In our series, 15 patients were injured with rifle bullet and three were injured with handgun 
bullet. CSF fistula and infection in patients injured with rifle bullet were mostly observed in our study because of the large cavity created by the bullet itself.

The most vulnerable region of the human body are the spine and the spinal cord. Tumours and traumas of the spine usually result in significant morbidity ${ }^{(16,17)}$. Cervical spine is the upper part of the spinal column. Although injuries to the cervical spinal cord is relatively rare, yet it is associated with severe neurological deficits ${ }^{(15)}$. Variations of the cervical spine make the management of cervical GSW really challenging because of its complex structure ${ }^{(16)}$. Spinal nerve roots leave the spinal cord from the relevant segment. However, segments of the spinal cord do not correspond to the respective vertebral level. Spinal anatomical variations exist in terms of the segment and the level of vertebra ${ }^{(18)}$. Therefore, the neurological deficits secondary to SGW vary because of the involved segment of the spine and may confuse the surgeon. Nerve plexuses formed by the spinal nerve roots may also be involved after the injury ${ }^{(19,20)}$. Brachial and lumbar plexuses may be injured after SGW to the cervical and lumbar spine ${ }^{(19)}$. Careful radiological and neurological examinations predict the level of injury better. A good anatomical knowledge of the nervous system will help achieve better neurological outcome after injury.

Neurological examination is required for deciding the type of treatment and also for the prediction of neurological condition of the patient after the treatment $t^{(7,8,10,11)}$. The major signs of a spinal injury are pain and neurological deficits ${ }^{(3,7,8)}$. Back pain is the common complaint among patients with lumbar SGW(21). American Spinal Injury Association scoring system is popularly used for the clinical assessment of $\mathrm{SGW}^{(3)}$. It is helpful for objective evaluation of patients both in preoperative and postoperative periods. Plain X-rays are mostly used for the initial evaluation of SGW. Anteroposterior and lateral X-rays can detect foreign bodies and major spinal fractures. The spinal stability can be examined by dynamic X-rays (in flexion and extension) $(10,11)$. CT and MRI are used for the detailed evaluation of SGW(12). CT scan reveals the injury level and structure of wound-causing agent (metal or others). MRI is useful for the detection of the spinal cord injury and soft tissue lesions such as abscess or pseudomeningocele. However, MRI is contraindicated in the presence of metallic fragment.

Medical treatment of SGW includes tetanus prophylaxis, antibiotics and steroids. Broad-spectrum antibiotics should be initiated immediately at least 48-72 hours after SGW. High-dose corticosteroids have been advocated in patients with spinal cord injury for many years. However, many studies have questioned their use because of the risks associated with complications and side effects and lack of evidence for neurological improvement $^{(13)}$. Experimental studies advocated splenectomy as a prophylactic treatment for spinal cord injury ${ }^{(22)}$. However, this technique is not useful in SGW. Some authors suggested the use of mannitol in the management of spinal cord injury, but there is no evidence in clinical practice yet ${ }^{(23)}$. Thus, there is still no definitive medical treatment method used for spinal cord injury.

Surgical treatment is the gold standard for SGW. However, the indications of surgery are important to obtain a satisfactory outcome. The main indications of surgical treatment are CSF fistula and progressive neurological deficit associated with spinal cord compression as performed in our series ${ }^{(4,5,7,8,11)}$. The main complication of SGW and CSF fistula is infection. Spinal abscesses may develop after surgery ${ }^{(24,25)}$. Continuous lumbar drainage may be performed in patients with CSF fistula who were not treated surgically. Antibiotic-impregnated catheters may be used for the prevention of CSF infection ${ }^{(26)}$. Spinal instability caused by damaged anterior and posterior elements of the spine is another indication of surgery ${ }^{(10,11,27)}$.

Bilgiç et al.(10) reported their experience with 27 male patients with SGW and concluded that patients with incomplete and/or lumbar fracture had better prognosis for functional recovery when surgery was performed early. Şehirlioğlu et al.(11) presented 19 patients with spinal fracture caused by SGW and concluded that early reduction and stabilisation after unstable spinal fractures enable great utilities for mobilisation and rehabilitation of the patients. Kahraman et al.(7) analysed 106 patients with spinal missile injury from war zones and concluded that surgical treatment was not essential for SGW; however, it may be required for patients with CSF fistula, infection and spinal instability, and rapid neurological deterioration. Duz et al. ${ }^{(8)}$ presented the surgical outcome of 122 patients with spinal missile injuries and pointed out that anteroposterior and oblique trajectories should be accepted as highly infective injuries in the lumbar region, but side-to-side trajectory missile injuries are usually unstable and require stabilisation surgery. Our results are similar with those of previous studies.

\section{Study Limitations}

The relatively low number of patients and lack of statistical analysis are the limitations of our study.

\section{CONCLUSION}

Surgical treatment is the gold standard for the management of SGW in cases of CSF fistula and progressive neurological deficit. Spinal instability is another indication for surgical intervention. Infection and neurological deficit are main complications. Prospective clinical studies are needed to improve the surgical outcomes of patients with SGW.

\section{Ethics}

Ethics Committee Approval: The study was performed by the ethical standards of the 1964 Declaration of Helsinki and approved by the University of Health Sciences Gülhane Medical Research Ethics Committee Medical Research Ethics Committee (Approval date: 30.06.2020, approval number: 2020/296).

Informed Consent: Written informed consent was obtained to publish the data.

Peer-review: Externally and internally peer-reviewed. 


\section{Authorship Contributions}

Surgical and Medical Practices: A.K., S.Y., Concept: A.K., Design: A.K., Data Collection or Processing: A.K., S.Y., Analysis or Interpretation: A.K., Literature Search: S.Y., Writing: A.K.

Conflict of Interest: No conflict of interest was declared by the authors.

Financial Disclosure: The authors declared that this study received no financial support.

\section{REFERENCES}

1. Abbas A, Aziz HF, Rizvi R, Rehaman L, Javeed F, Afzal A. Gunshot acquired spinal cord injury in civilians. Turk Neurosurg. 2019;29:506-12.

2. Escamilla JAC, Ross JÁG, Atanasio JMP, Martínez GC, Cisneros AG, Avila JJ. Spinal gunshot wounds: Pattern and associated lesions in civilians. Asian Spine J. 2018;12:648-55.

3. Alaca R, Yilmaz B, Goktepe AS, Yazicioglu K, Gunduz S. Military gunshot wound-induced spinal cord injuries. Mil Med. 2002;167:926-8.

4. Bono CM, Heary RF. Gunshot wounds to the spine. Spine J. 2004;4:230-40.

5. Kitchel SH. Current treatment of gunshot wounds to the spine. Clin Orthop Relat Res. 2003;408:115-9.

6. Jakoi A, lorio J, Howell R, Zampini JM. Gunshot injuries of the spine. Spine J. 2015;15:2077-85.

7. Kahraman S, Gonul E, Kayali H, Sirin S, Duz B, Beduk A, et al. Retrospective analysis of spinal missile injuries. Neurosurg Rev. 2004;27:42-5.

8. Duz B, Cansever T, Secer HI, Kahraman S, Daneyemez MK, Gonul E. Evaluation of spinal missile injuries with respect to bullet trajectory, surgical indications and timing of surgical intervention: a new guideline. Spine (Phila Pa 1976). 2008;33:E746-53.

9. Le Roux JC, Dunn RN. Gunshot injuries of the spine--a review of 49 cases managed at the Groote Schuur Acute Spinal Cord Injury Unit. S Afr J Surg. 2005;43:165-8.

10. Bilgiç S, Yurttaş Y, Özkan H, Kürklü M, Erşen Ö, Şehirlioğlu A. Omurga ateşli silah yaralanmalarında erken dönem sonuçlarımız. The Journal of Turkish Spinal Surgery. 2008;19:407-16.

11. Şehirlioğlu A, Aydoğan N, Kırdemir V, Ateşalp S. Treatment principles in spinal fractures due to gunshot wounds. JTSS. 1994;5:115-7.

12. Izci Y, Tehli $O$. Terörde ve savaşta kraniyal ve spinal kord yaralanmaları. Okmeydanı Tıp Dergisi. 2017;33:21-39.

13. de Barros Filho TE, Cristante AF, Marcon RM, Ono A, Bilhar R. Gunshot injuries in the spine. Spinal Cord. 2014;52:504-10.
14. Isiklar ZU, Lindsey RW. Gunshot wounds to the spine. Injury. 1998;29(Suppl 1):SA7-12.

15. Beaty N, Slavin J, Diaz C, Zeleznick K, Ibrahimi D, Sansur CA. Cervical spine injury from gunshot wounds. I Neurosurg Spine. 2014;21:442-9.

16. Kaya S, Yilmaz ND, Pusat S, Kural C, Kirik A, Izci Y. Double foramen transversarium variation in ancient Byzantine cervical vertebrae: preliminary report of an anthropological study. Turk Neurosurg. 2011;21:534-8.

17. Baysefer A, Akay KM, Izci Y, Kayali H, Timurkaynak E. The clinical and surgical aspects of spinal tumors in children. Pediatr Neurol. 2004;31:261-6.

18. Canbay S, Gürer B, Bozkurt M, Comert A, Izci Y, Başkaya MK. Anatomical relationship and positions of the lumbar and sacral segments of the spinal cord according to the vertebral bodies and the spinal roots. Clin Anat. 2014;27:227-33.

19. Secer HI, Solmaz I, Anik I, Izci Y, Duz B, Daneyemez MK, et al. Surgical outcomes of the brachial plexus lesions caused by gunshot wounds in adults. J Brachial Plex Peripher Nerve Inj. 2009;4:11.

20. Izci Y, Gurkanlar D, Ozan H, Gonul E. The morphological aspects of lumbar plexus and roots: An anatomical study. Turk Neurosurg. 2005; 15:87-92.

21. Izci Y, Taskaynatan MA. Management of lower back pain in young Turkish recruits. Mil Med. 2004;169:824-8.

22. Temiz C, Solmaz I, Tehli O, Kaya S, Onguru O, Arslan E, et al. The effects of splenectomy on lipid peroxidation and neuronal loss in experimental spinal cord ischemia/reperfusion injury. Turk Neurosurg. 2013;23:67-74.

23. Baysefer A, Erdogan E, Kahraman S, Izci Y, Korkmaz C, Solmaz I, et al. Effect of mannitol in experimental spinal cord injury: an ultrastructural and electrophysiological study. Neurol India. 2003;51:350-4.

24. Baysallar M, Izci Y, Kilic A, Avci IY, Senses Z, Doganci L. A case of ventricular drainage infection with a rare pathogen in cerebrospinal fluid: vancomycin-resistant Enterococcus faecium. Microb Drug Resist. 2006;12:59-62.

25. Izci Y. Lumbosacral spinal epidural abscess caused by Brucella melitensis. Acta Neurochir (Wien). 2005;147:1207-9.

26. Secer HI, Kural C, Kaplan M, Kilic A, Duz B, Gonul E, et al. Comparison of the efficacies of antibiotic-impregnated and silver-impregnated ventricular catheters on the prevention of infections. An in vitro laboratory study. Pediatr Neurosurg. 2008;44:444-7.

27. Ozer $H$, Akçalı $O$, Koçak A. Spinal instability following gunshot wounds. Report of two cases. JTSS. 1999;10:19-22. 